\title{
articles
}

\section{Human rights abuses at a psychiatric hospital in KwaZulu-Natal}

D L Mkize, MB ChB,DCH, MFGP,DFM, MMed (Psych) Department of Psychiatry, University of KwaZulu-Natal, Durban, and Head of Mental Health Services KwaZuluNatal

Background. Following allegations of human rights abuses at a psychiatric hospital in Pietermaritzburg, KwaZulu-Natal, that were reported in one of the local newspapers, the national and provincial Ministers of Health visited the hospital. Because of the seriousness of the allegations, the national Minister of Health established a Committee of Enquiry to investigate the allegations. The 7 committee members included experts in mental health care services, legal services, public service sector, a hospital board member, and a representative of the community.

Objectives. The terms of reference of the Committee of Enquiry were to investigate allegations of human rights abuses of psychiatric patients at the hospital, and to report their findings to the Minister, in line with the media reports.

Methods. The public was invited through notices in the print and electronic media to make submissions relating to the allegations. Interviews and site inspections were conducted. Written submissions were received. Legislative and regulatory frameworks were studied. Reports of previous commissions as well as hospital records were analysed.

Findings. The findings of the Committee confirmed all media allegations of human rights abuses as appearing in the terms of reference. In addition, the Committee identified the following systemic defects: (i) weak management over a long period of time; (ii) absence of a hospital board; (iii) inadequacies in the physical layout and quality of facilities; (iv) abuse of staff by patients; $(v)$ staff reporting on duty under the influence of alcohol; (vi) high rate of absenteeism; (viii) shortage of staff; (viii) lack of discipline; (ix) evidence of racism, nepotism and favouritism; and ( $x$ ) strained relations between the management and unions.

Recommendations. The Committee recommended that remedial and preventive measures be undertaken as a matter of urgency to combat human rights abuses and address deficiencies in the system.
On Saturday 5 February 2005 one of the local newspapers reported allegations of human rights abuses at a psychiatric hospital. On Monday 7 February 2005 the national and provincial Ministers of Health visited the hospital.

After meeting the hospital management and conducting an in loco inspection, the national Minister of Health addressed the hospital community. She had been shocked by the newspaper report and had viewed the allegations seriously, more especially as the new Mental Health Care Act was being implemented. She expressed that there should be expeditious intervention.

\section{Committee of Enquiry}

The Minister established a Committee of Enquiry to investigate the allegations and report back in 3 weeks' time. After 3 weeks the Chairman of the Committee delivered an interim report and requested an extension of the time frame as issues requiring intensive investigation had come to light.

\section{Members of the Committee}

The seven members of the Committee were as follows: Head of the Department of Psychiatry, Nelson Mandela School of Medicine, and Head of Mental Health Services KwaZulu-Natal (Chairman); Resident Commissioner KwaZulu-Natal, Public Service Commission (Deputy Chairperson); Member of Townhill Hospital Interim Board; Programme Manager Mental Health and Substance Abuse, KwaZulu-Natal; Head of the Deparment of Psychology, University of Limpopo (Medunsa Campus); Specialist Psychiatrist in private practice, President Elect of the Sociely of Psychiatrists of South Africa; and the Chief General Manager, Legal Services in KwaZulu-Natal.

\section{Terms of reference}

The mandate of the Committee of Enquiry was to investigate allegations of human rights abuses of psychiatric patients at the hospital. In line with the media reports, the following issues were investigated: (i) neglect of patients; (ii) allegations of sexual abuse among patients, with staff turning a blind eye; (iii) physical abuse of patients by staff members; (iv) theft of patients' food; ( $v$ ) theft of patients' belongings; (vi) patients sleeping on the floor; (vii) female patients not allowed access to underwear; (viii) physical abuse of staff members by patients; (ix) staff reporting on duty under the influence of alcohol; $(x)$ high rate of staff absenteeism; and (xi) any other matters the Committee deemed necessary. 


\section{Methods}

A public notice of the enquiry was posted in the local media inviting interested or affected parties to participate. The notice in the print media was complemented by announcements on local radio stations where members of the public were invited to submit personal experiences of human rights abuses at the hospital to the Committee.

The following documents were studied: media reports; the Constitution of the Republic of South Africa Act No. 108 of 1996; the National Health Act of 2004; the Mental Health Care Act No. 17 of 2002; the Norms Manual for Severe Psychiatric Conditions; the Strategic and Implementation Plan for Delivery of Mental Health Services in KwaZulu-Natal of 2003; the Batho Pele Principles; the Patients Rights Charter; the Public Service Act of 1994; Health is a Human Right; the KwaZulu-Natal Minister of Health Budget Speech 2005; and the International Council of Nurses Code of Ethics for Nurses of 1953.

The following reports of previous commissions were reviewed: the Retief Commission of 1996/1997, the Manzi/Cassimiee Commission of 2002, and the Human Rights Commission of 2005

Over a period of 6 weeks the Commission met once a week to listen to oral submissions, conduct interviews and analyse written submissions. Members of the public, union representatives, patients and hospital staff were interviewed. A professional stenographer recorded all interviews and made hard-copy transcripts of the interviews.

The approach adopted by the Committee also included in loco inspection of the hospital wards and precincts. Further interviews were conducted on site with a random selection of patients and staff.

The methodology further included scrutiny of hospital records, with special emphasis on patient files, incident reports, human resources records, and sick leave and off-duty register to test the reported allegations

\section{Findings}

The findings are presented in the order of the terms of reference.

\section{Neglect of patients}

There was overwhelming evidence of patients being neglected by staff.

\section{Sexual abuse}

There was evidence of patients being sexually abused by staff.

\section{Physical abuse}

The Committee of Enquiry received information substantiating the allegations of physical and verbal abuse of patients by staff and of staff by patients.

\section{Theft of patients' food and belongings}

There was ample evidence of staff stealing patients' food and belongings.

\section{Patients sleeping on the floor}

The committee's in loco inspection of the hospital revealed evidence of floor beds and patients sleeping on them.

\section{Female patients not allowed access to underwear}

The allegations were confirmed. Nurses agreed that female patients sometimes did not wear panties because of shortages and because of their psychotic state.

\section{Abuse of staff members by patients}

The Committee found evidence of verbal, physical and emotional abuse of staff members by patients. Patients abused staff members because of the nature of their illness. There were no trauma counselling services and no satisfactory Employee Assistance Programme

\section{Staff reporting on duty under the influence of alcohol}

There was overwhelming evidence from hospital records and interviews supporting allegations of staff coming to work under the influence of alcohol.

\section{High rate of staff absenteeism}

The Committee found evidence of a high rate of absenteeism. A disturbing pattern was the escalation of absenteeism after the 15 th and 30th of each month, these being paydays.

\section{Additional findings}

\section{Poor patient management}

During the in loco inspection the Committee found evidence of poor patient management by the doctors, with some patients prematurely transferred to the pre-discharge ward while they were 
still psychotic, and others not discharged when they were ready for discharge. Evidence was further confirmed in the interviews.

\section{Inadequate recreational facilities}

Patients were found to be spending most of their time in the wards, with little or no exercise and recreation: No reading material was supplied to stimulate those who were recovering. Television was usually provided. The beautiful and undulating hospital gardens were not used in the therapy of the patients.

\section{Racism, nepotism and favouritism}

There was overwhelming evidence of racism, nepotism and favouritism at the hospital on the part of middle management, and by doctors with regard to employment, work allocation and clinical management. Ward accommodation reflected a racial bias.

\section{Staff shortage and poor work conditions}

Staff shortage and poor work conditions were major problems in the hospital and were highlighted in almost all the interviews and confirmed during the inspection. The ratio of nursing staff to patients left much to be desired. There were 3 nurses to 26 patients - 1 nursing sister, and 2 staff nurses/nursing assistants. There were 2 psychiatrists to 250 patients. This was clearly inadequate as psychiatric patients need constant attention, particularly in the acute phase. Such patients are often restless and some may be aggressive.

Staff shortage was a major problem at all levels. On paper the hospital had a staff complement of 336. However, at the most, existing staff numbered 230 due to factors such as budgetary constraints and unavailability of registered psychiatric nurses, particularly males, as the majority of them go to the prison department or overseas. The current staff-patient ratio was 4 nurses to 30 patients. When the nurses and doctors compared themselves with their overseas counterparts there was a marked difference in staff-patient ratios. For example, in Australia there are usually 6 psychiatrists to 26 patients, and 1 psychiatric nurse to 2 patients.

This kind of patient load was causing frustration and demorali-sation among those staff members who were highly motivated. Generally, staff were of the opinion that they were doing a thankless job. The unions also complained about the hospital being short staffed, with volunteers coming in to assist having no certainty that they would be employed in the near future. This also contributed to low morale and lack of effectiveness on the part of the staff.
Because of staff shortage, staff members were not always available to supervise patients adequately. The Committee heard of an incident in which a young girl pushed her head through a broken window. Her head was trapped and she bled to death.

\section{Lack of discipline}

The commission found that there was inconsistency in the way the hospital management addressed grievances and cases of misconduct.

\section{Strained relations between management and unions}

Evidence indicated that unions were perceived to be a stumbling block in the handling of misconduct. On the other hand, unions maintained that it was their duty to represent their members.

\section{Media reports}

The Committee expressed awareness of the fact that spectacular and startling headlines are used to sell newspapers. The Committee noted that the most publicised stories are about things that go wrong, with scant attention given to things that go right. These reports can be very damaging to institutions and the government as they serve to create inaccurate and misleading images in the mind of the public. People can be led to fear the institution and lose faith in the government's provision of health services. Such reportage also leads to low staff morale.

The Committee expressed the opinion that most of the above adverse findings were a result of poor management over a number of years and the absence of an effective hospital board. Furthermore there was no Provincial Director of Mental Health and Substance Abuse to support the hospital management. Lamentably, the National Department of Health also did not have a National Director of Mental Health and Substance Abuse to ensure a quality mental health care service at the hospital. Therefore the Committee strongly recommended that hospital management should be strengthened by advertising and filling all the vacant management posts, and that the hospital board should be put in place without delay.

\section{Recommendations}

Recommendations were itemised as follows:

\section{Neglect of patients}

1. The Patients Rights Charter should be supported, implemented and monitored, and every morning these principles should be read and internalised by the staff on duty. Further, the Charter 
principles should be communicated regularly to patients as part of ward routine to promote monitoring by patients.

2. Service standards should be clearly defined and prominently displayed at service delivery points. This would make it easier for the public to recognise what constitutes acceptable professional behaviour.

3. Staff identification tags on uniforms/clothing should be implemented to improve professionalism and security at the workplace.

4. There should be proper patient identification, including name tags and contact telephone numbers of the institution.

5. Accurate records should be kept of patients' movements, possessions and medication.

6. Communication and liaison with the South African Police Services (SAPS) and neighbouring institutions should be improved for speedy return of absconding patients.

7. The contracted security company should undertake mandatory regular patrols of the hospital perimeter and grounds for improved security.

8. Close-circuit television cameras should be installed at strategic points and there should 24-hour monitoring by the security company.

\section{Sexual abuse}

1. The committee recommended that the staff member who was dismissed for raping a patient should be charged accordingly, and the employer should refer this matter to the South African Police Services

2. All cases of alleged sexual and physical abuse should be handled according to the protocol, which would ensure that the patient be examined by at least 2 independent medical practitioners.

3. All suspected or reported cases of sexual abuse should be handed over to the SAPS.

4. There should be separate wards for children and adolescents to avoid sexual abuse.

5. Condoms should be readily available to patients.

\section{Physical abuse}

1. Staff should be trained on how to handle violent and aggressive patients.
2. Protocols on how to handle acutely disturbed patients should be made available to staff members.

3. The Committee strongly recommended that all cases of physical abuse be reported to the SAPS.

\section{Theft of patients' food and belongings}

The Committee found it difficult to recommend on theft of patients' food because of lack of clearly defined procedures in handling patients' food. A full inventory of the patients' belongings should be kept and updated as patients are moved from ward to ward.

\section{Patients sleeping on the floor}

This practice was more prevalent in the seclusion rooms, therefore the Committee recommended that beds should be fixed to the floor.

\section{Female patients not allowed access to underwear}

The Committee recommended that disposable underwear be purchased for psychotic patients.

\section{Abuse of staff members by patients}

1. Staff should be aware that because of the nature of their illness, mentally ill patients tend to be abusive. Therefore patients should be treated with tact, tolerance and compassion.

2. Protocols should be followed in handling aggressive patients.

3. In recognition of the dangers of the work environment, the incentive of a danger allowance should be reinstated.

\section{Staff reporting on duty under the influence of alcohol}

1. Breathalyser tests should be kept in the matron's office; any staff member suspected of intoxication should be reported immediately and the breathalyser test should be administered.

2. All suspected cases of intoxication should be examined by a doctor on call.

3. An Employee Assistance Programme should be instituted.

4. Due processes should be implemented, including disciplinary action and dismissal.

\section{High rate of absenteeism}

1. The high rate of absenteeism was found to be directly related to alcohol abuse, HIV/AIDS, poor working conditions, annual leave 
conditions for nurses, and a poorly functioning leave committee.

2. The following measures were proposed to address the issue of poor working conditions: infrastructure upgrade, danger allowance, all vacant posts to be advertised and filled, proper supervision, clear career-pathing, and improved relationship with unions.

3. The institution should plan even distribution of leave for nurses throughout the year.

4. The present leave committee should be disbanded and a new committee reporting to the hospital board should be established.

5. All doctors' certificates should be scrutinised by the new leave committee and irregular certificates should be reported to the Health Professions Council of South Africa.

\section{Additional recommendations}

\section{Poor patient management}

1. Guidelines should be developed to assist practitioners to maintain a balance between carrying out their duty of care and getting enmeshed in the affairs of health care users thereby running the risk of violating human rights.

2. Co-ordinated interdepartmental collaboration should be fostered between the Departments of Health and Social Development in the provision of mental health services. The Department of Social Development should be involved in the humane placement of geriatric patients being kept illegally at the hospital.

3. The hospital should institute sustained mental health care campaigns incorporating a human rights culture and a positive image of the hospital.

\section{Specific cases}

1. The Committee recommended that Mrs X be discharged immediately from the hospital, and that the decision taken not to discharge her should be referred to the Review Board and the Health Professions Council of South Africa as a violation of human rights.

2. Mr X should have access to his hospital records in accordance with the Access to Information Act.

\section{Inadequate recreational facilities}

1. Reading material should be provided for patients ready for discharge.
2. More sporting activities should be developed to cater for the various needs of patients, e.g. a football team for patients and staff.

3. Optimal use should be made of the beautiful grounds of the hospital. A walking trail should be developed and used for exercise and milieu therapy.

4. Occupational therapists should be involved in the care of patients.

5. The community support network of each patient should be involved as early as possible in the rehabilitation of the patient. This would promote the reintegration of the patient into his/her community.

\section{Racism, nepotism and favouritism}

A designated Transformation Committee should be formed as a matter of urgency to deal with these anomalies and to educate and train people on transformation. Further, the Department of Health should investigate the management style at the hospital and appropriate action should be taken.

\section{Staff shortage}

1. Strict adherence to the Norms Manual for Severe Psychiatric Conditions issued by the Department of Health should be enforced.

2. All vacant posts should be advertised and filled.

3. Orderlies should be employed.

4. The Department of Health, the Department of Psychiatry and the Department of Nursing should meet as soon as possible with a view to developing a curriculum to train mid-level mental health workers.

5. A psychiatric elective should be added to the training of staff nurses.

6. There should be a conscious plan to recruit male nurses in the field of psychiatry.

7. The retention strategy to prevent exodus of nurses should include plans for nurses to go overseas for a certain period to gain experience and be reabsorbed on return.

\section{Lack of discipline}

The ICN Code of Ethics for nurses should be put in place and practised, and any lack of discipline should be reported to the South African Nursing Council. 


\section{Strained relations between management and unions}

There should be a clear recognition agreement between unions and management to regulate their relationship.

\section{Limitations of the Committee}

1. The Committee was unable to interview the previous Hospital Manager, a main player in the previous poor management as mentioned above.

2. Social workers and psychologists were also not interviewed. It is lamentable that they did not voluntarily come forward to make presentations.

3. The renovations at the hospital were already underway when the Committee conducted an in loco inspection. As a result, in some instances media reports could not be verified.

4. The Committee took longer than expected to finish its work as mandated due to the fact that members of the Committee were fully employed elsewhere.

\section{Conclusion}

The mark of good defence of the poor, marginalised and underprivileged is a commitment to do what is right, just and fair at all times. The Constitution of the Republic of South Africa (Act No. 108 of 1996) qualifies without peer in this regard. There are laws, regulations, principles and ethical codes promoting respect for human rights and quality patient care. The tragedy is lack of implementation, compliance, enforcement and oversight bodies to ensure that these benefit mental health care users.
Although mental health impacts on all aspects of life in the country, mental health care is trivialised in a way that sabotages the good intentions of the law.

A study of departmental strategic plans and budgets reveals such trivialisation, which contributes to a denial of patient access to quality mental health care.

The hospital is an old institution, which is no longer structurally suitable as a health care facility. Drastic transformation is required of the facility itself, management, and the service culture among the staff. The institution predisposes patients to human rights abuses, and contributes to staff demoralisation, burnout and the vicious circle of staff turnover.

Resolving the problems identified at the hospital requires an intersectoral, interdepartmental and multidisciplinary approach. The Department of Health must work in collaboration with the Social Welfare Department, Department of Education and Department of Works in their respective roles to produce a sustainable and innovative solution in the interests of quality patient care.

The hospital board must monitor and evaluate implementation of the recommendations of this Committee. At a higher level the provincial and national Heads of Health Care must demonstrate commitment to sustained support of the laws and regulations that are in place to improve quality health care.

The author would like to thank the Committee members for their contribution, and the participants who so willingly agreed to be interviewed. Further thanks go to the secretariat Ms B Dlamini for her expert assistance and logistical support. 